\title{
Maternal Milk Reduces Severity of Necrotizing Enterocolitis and Increases Intestinal IL-10 in a Neonatal Rat Model
}

\author{
BOHUSLAV DVORAK, MELISSA D. HALPERN, HANA HOLUBEC, KATERINA DVORAKOVA, \\ JESSICA A. DOMINGUEZ, CATHERINE S. WILLIAMS, YOLANDA G. MEZA, \\ HANA KOZAKOVA, AND ROBERT S. MCCUSKEY
}

Department of Pediatrics and Steele Memorial Children's Research Center [B.D., M.D.H., J.A.D., C.S.W., Y.G.M, H.K., R.S.M.], Department of Microbiology \& Immunology [H.H., K.D.], and Department of Cell Biology \& Anatomy [B.D., R.S.M.], University of Arizona, Tucson, Arizona 85724, U.S.A.

\begin{abstract}
Necrotizing enterocolitis (NEC) is a devastating intestinal disease of premature infants. Maternal milk has been suggested to be partially protective against NEC; however, the mechanisms of this protection are not defined. The aim of this study was to examine the effect(s) of artificial feeding of rat milk (RM) versus cow milk-based rat milk substitute (RMS) on the development of NEC in a neonatal rat model and elucidate the role of inflammatory cytokines in NEC pathogenesis. Newborn rats were artificially fed with either collected RM or RMS. Experimental NEC was induced by exposure to asphyxia and cold stress and evaluated by histologic scoring of damage in ileum. Intestinal cytokine mRNA expression was determined by real-time PCR. Cytokine histologic localization was performed by confocal microscopy. Similar to human NEC, artificial feeding of RM reduces the incidence and severity of NEC injury in neonatal rats. Freezing and thawing of collected RM did not eliminate the protective effect of maternal milk. Ileal IL-10 expression was significantly increased in the RM group compared with RMS.
\end{abstract}

\section{ABSTRACT}

Increased IL-10 peptide production was detected in the RM group with signal localized predominantly in the cytoplasm of villus epithelial cells. These results suggest that the protective effect of maternal milk is associated with increased production of anti-inflammatory IL-10 in the site of injury. Better understanding of the mechanisms underlying these protective effects could be beneficial either in the prevention of NEC or in the development of future therapeutic strategies to cure NEC. (Pediatr Res 53: 426-433, 2003)

EM, electron microscopy

IBD, inflammatory bowel disease

IFN- $\boldsymbol{\gamma}$, interferon- $\gamma$

NEC, necrotizing enterocolitis

RMS, rat milk substitute

TGF- $\boldsymbol{\beta}$, transforming growth factor- $\beta$

TNF- $\alpha$, tumor necrosis factor- $\alpha$
Neonatal necrotizing enterocolitis (NEC) is a devastating gastrointestinal disease predominantly of prematurely born infants. In addition to prematurity, other factors contribute to the development of NEC, including enteral feeding, intestinal hypoxia/ischemia, and bacterial colonization (1, 2). The incidence of NEC varies with gestational age, being highest among smaller, more premature neonates with a

Received May 20, 2002; accepted September 25, 2002.

Correspondence: B. Dvorak, Ph.D., Department of Pediatrics, University of Arizona, 1501 N. Campbell Avenue, P.O. Box 245073, Tucson, AZ 85724-5073, U.S.A.; e-mail: dvorakb@peds.arizona.edu

Current address for H.K.: The Academy of Sciences of the Czech Republic, Institute of Microbiology, Novy Hradek, Czech Republic.

This work was supported by the National Institute of Child Health and Human Development Grants HD26013 and HD39657 (to B.D.), the University of Arizona Vice President for Research and Graduate Studies Award (to B.D.), and the Grant Agency of the Czech Republic A5020101 (to H.K.).

DOI: 10.1203/01.PDR.0000050657.56817.E0 birth weight $<1500 \mathrm{~g}$ (3). The majority of infants with NEC have been fed enterally with formula before disease onset. Thus, it has been proposed that the composition of infant formula and the immaturity of gastrointestinal motility, absorptive, or host defense processes contribute to the high risk and increased susceptibility of premature infants to develop NEC (4). Clinical studies indicate that maternal milk plays a protective role in the pathogenesis of NEC (2, 5-8). Maternal milk provides hormones, cytokines, growth factors, and nucleotides that facilitate the maturation of the intestinal mucosal barrier and other essential intestinal functions (9). However, the factor(s) responsible for the protective effect of maternal milk remain to be identified. Recently, we showed that supplementation of formula with epidermal growth factor, a peptide normally present in maternal milk but absent in infant formula, is highly protective against NEC in a rat experimental model (10). 
Several animal models have been developed to study NEC, including pigs $(11,12)$, dogs (13), rabbits (14-16), mice (17), and rats $(10,18-20)$. Among them, the rat NEC model has been suggested as one of the best experimental models to study this disease (20-22). In this model, NEC is induced in neonatal rats via enteral feeding of cow milk-based rat milk substitute (RMS) coupled with asphyxia and cold stress. With the use of this method, $\sim 80 \%$ of neonatal rats develop NEC (10). In mammalian species born after short gestation (including mouse and rat), the development of many essential intestinal functions occurs in the early postnatal period. In contrast, in mammals with a long gestation period (humans, sheep, pigs), intestinal development occurs predominantly in utero. Therefore, neonatal rat intestine is highly relevant to the study of diseases related to immature human gut (23). Consequently, the neonatal rat model encompasses the two most essential risk factors for NEC - immaturity and enteral feeding of formula - and is currently the only animal model that incorporates developmental aspects of the disease.

Immaturity of intestinal mucosal immunity and epithelial barrier functions likely play a critical role in NEC pathogenesis (24). In mature bowel, the intestinal environment is capable of producing an array of cytokines important in the development and control of inflammatory responses (25). In contrast, the immaturity of the neonatal intestinal immune system is evidenced by decreased numbers of immune cells $(26,27)$. Therefore, the production of proinflammatory cytokines, such as IL-6, IL-12, IL-18, and tumor necrosis factor- $\alpha$ (TNF- $\alpha$ ) (2830 ) and anti-inflammatory cytokines such as IL-10 and transforming growth factor- $\beta$ (TGF- $\beta$ ) (31-33) by intestinal epithelial cells is highly relevant to the NEC etiology $(28,31,33)$. Indeed, recent results from clinical studies indicate elevated serum cytokine levels in patients with severe NEC $(30,31)$. Moreover, we recently reported increased production of IL-18 by ileal epithelium of neonatal rats with severe NEC injury (34).

The aim of the present study was to compare enteral feeding of rat milk (RM) and RMS on the development and progression of NEC in the neonatal rat model. We evaluated the incidence and severity of NEC, the changes in cytokine gene expression, and histologic localization in asphyxia/cold-stressed neonatal rats that were either artificially fed with collected RM or RMS or dam fed (DF).

\section{METHODS}

Experimental design and RM collection. Newborn Sprague Dawley rats were collected immediately after birth to prevent suckling of maternal milk and assigned to three experimental groups: artificially fed with RMS, artificially fed with collected $\mathrm{RM}$, and DF. The RMS diet was prepared as previously described in detail by Dvorak et al. (35). All experimental groups were exposed to asphyxia/cold stress to develop experimental NEC (10). Ninety-six hours from the beginning of each study, all animals were killed and intestinal tissue was collected and analyzed. Banked RM was collected by manual expression from anesthetized mothers on days $2-8$ of lactation. The pups were separated from their mothers approximately
4-6 h before milking. After s.c. injection of a mixture of ketamine, xylazine, and acepromazine, the mother rats were given 2 units of oxytocin (Sigma Chemical Co., St. Louis, MO, U.S.A.) i.p. Twenty minutes later, milk was expressed gently into polypropylene tubes and stored at $-70^{\circ} \mathrm{C}$ for no more than 6 weeks before use. Each rat was used only once for the harvesting of RM.

Animal model of NEC. The experimental protocol was approved by the Animal Care and Use Committee of the University of Arizona (A-324801-95081). Forty Sprague Dawley neonatal rats (Charles River Labs, Pontage, MI, U.S.A.) originating from six separate litters were used in this study. For inducing the development of clinical and pathologic signs of NEC, neonatal rats were stressed twice daily with asphyxia (breathing $100 \%$ nitrogen gas for $60 \mathrm{~s})$ followed by cold $\left(4^{\circ} \mathrm{C}\right.$ for 10 min) stress $(10,18,36)$. Rats in the RMS and RM groups were hand-fed every $3-4 \mathrm{~h}$ during the first $48 \mathrm{~h}$ with gradually increasing volume of both diets (RMS or RM) from 0.1 to 0.2 $\mathrm{mL}$ of diet per feeding. The hand-fed method was replaced with mechanized artificial feeding for an additional $48 \mathrm{~h}$ (35). The volume of RMS or RM to be given to each animal was calculated to deliver $\sim 25 \%$ of body weight per 24 -h period. Body weight gain was recorded daily. After 96 h, all surviving animals were killed via decapitation.

Tissue harvest and NEC evaluation. After termination, the gastrointestinal tract was carefully removed and the small intestine was visually evaluated for typical signs of NEC (intestinal discoloration, intestinal hemorrhage, ileal distention, and/or ileal stenosis). A 2-cm section of distal ileum proximal to the ileocecal valve from each animal was fixed overnight in $70 \%$ ethanol, paraffin-embedded, sectioned at 4-6 $\mu \mathrm{m}$, and stained with hematoxylin and eosin for histologic evaluation of NEC. The rest of ileum was snap-frozen in liquid nitrogen for further biochemical and gene expression analysis. Histologic changes in ileal architecture were scored by a blinded evaluator and graded as follows: 0, normal, no damage; +1 , slight submucosal and/or lamina propria separation; +2 , moderate separation of submucosa and/or lamina propria and/or edema in submucosal and muscular layers; +3 , severe separation of submucosa and/or lamina propria and/or severe edema in submucosa and muscular layers, region villous sloughing; +4 , loss of villi with necrosis [see details in Dvorak et al. (10)].

Immunohistology of IL-10. Ileal sections were deparaffinized in three changes of xylene and rehydrated in a graded series of ethanol dilutions. Sections were blocked with $5 \%$ BSA (Sigma Chemical Co.) for $10 \mathrm{~min}$, then incubated with 5 $\mu \mathrm{g} / \mathrm{mL}$ of the polyclonal goat anti-rat IL-10 antibodies (Santa Cruz Biotechnology, Santa Cruz, CA, U.S.A.) in PBS solution with 1\% BSA for an additional $60 \mathrm{~min}$. After three PBS washes, biotinylated rabbit anti-goat secondary antibody (Vector Laboratories) was applied for $60 \mathrm{~min}$, followed by incubation with Cy5-conjugated streptavidin for $1 \mathrm{~h}$. Nuclei were labeled after RNase digestion using YOYO-1 (Molecular Probes Inc., Eugene, OR, U.S.A.), as previously described (37). Coverslips were then mounted using mounting media (DAKO Corp., Carpinteria, CA, U.S.A.), and slides were stored at $4^{\circ} \mathrm{C}$. A laser scanning confocal microscope (LEICA TSD-4D, Heidelberg, Germany) equipped with an argon- 
krypton laser was used to obtain images. The laser power, the voltage of the photomultiplier tube, and the number of line scans were constant so that fluorescent intensities of various samples could be compared. Control sections were treated with the same procedure except that they were incubated with $1 \%$ BSA (Sigma Chemical Co.) instead of the specific IL-10 antibodies. No signal was observed in controls. Sections from $\mathrm{DF}, \mathrm{RM}$, and RMS groups were simultaneously stained so that comparisons of staining intensities between groups could be assessed.

Scanning electron microscopy. Segments of distal ileum were fixed overnight at $4^{\circ} \mathrm{C}$ in $3 \%$ glutaraldehyde in $0.1 \mathrm{M}$ cacodylate buffer, rinsed in $0.1 \mathrm{M}$ cacodylate buffer, and incubated in $1 \%$ tannic acid in $0.15 \mathrm{M}$ cacodylate buffer for $1 \mathrm{~h}$. After cacodylate buffer rinse, samples were postfixed in $1 \%$ osmium tetroxide in $0.1 \mathrm{M}$ cacodylate buffer for $1 \mathrm{~h}$ and then washed in 0.1 $\mathrm{M}$ cacodylate buffer. Samples were dehydrated in graded series of ethanol (30-100\%) and dried using hexamethyldisilazane (Electron Microscopy Sci, Fort Washington, PA, U.S.A.) for $3 \mathrm{~min}$ then air dried. Samples were mounted onto aluminum stubs and sputter coated with gold and viewed using Philips XL 30 scanning electron microscope. Digital images were acquired using an FEI Microscope control software.

Stool occult blood. The detection of occult blood in the stool was performed using the guaiac test. A small quantity of stool was smeared on filter paper and mixed with $100 \mu \mathrm{L}$ of glacial acetic acid. Guaiac solution (100 $\mu \mathrm{L}$ of $1 \mathrm{~g}$ of gum guaiac in $5 \mathrm{~mL}$ of ethanol) and $100 \mu \mathrm{L}$ of $3 \% \mathrm{H}_{2} \mathrm{O}_{2}$ were added and mixed. The appearance and intensity of any blue or blue-green color was evaluated within 1-5 min and scored on a scale of $0-4$ by two independent, blinded evaluators. Deep blue color appearing within $1 \mathrm{~min}$ was graded 4 . Lesser degrees of color development occurring within 1-5 min were graded 3-1 (3, strong signal; 2 , moderate signal; 1 , small traces of blood in stools). No blood in stools (no color development) was scored as 0 . For minimizing the variability in analysis of grading, a no blood sample (0) and a systemic blood sample (4) were assayed as a standard range.

RNA preparation and real-time $R$ T-PCR assay. Total RNA was isolated from ileal tissue using the RNeasy Mini Kit (Qiagen, Santa Clarita, CA, U.S.A.) as described in the manufacturer's protocol. All samples were incubated with RNasefree DNase (20 U per reaction) for $10 \mathrm{~min}$ at $37^{\circ} \mathrm{C}$ to eliminate DNA contamination. RNA concentration was quantified by UV spectrophotometry at $260 \mathrm{~nm}$, and the purity was determined by the $\mathrm{A}_{260} / \mathrm{A}_{280}$ ratio (SPECTRAmax PLUS, Molecular Devices, Sunnyvale, CA, U.S.A.). The integrity of RNA was verified by electrophoresis on a $1.2 \%$ agarose gel containing formaldehyde $(2.2 \mathrm{M})$ and ethidium bromide in $1 \times$ MOPS buffer [40 mM MOPS ( $\mathrm{pH} 7.0$ ), $10 \mathrm{mM}$ sodium acetate, and 1 mM EDTA (pH 8.0)].

RT and real-time RT-PCR were performed specifically to quantify rat IL-10, IL-12, IL-18, TNF- $\alpha$, interferon- $\gamma($ IFN- $\gamma$ ), and TGF- $\beta$ steady-state mRNA levels. Single-stranded cDNA was reverse-transcribed from $1 \mu \mathrm{g}$ of total RNA in a $10-\mu \mathrm{L}$ reaction mixture, as previously described in detail (38). The amounts of total RNA used in the RT reactions were calculated from the absorbency at $260 \mathrm{~nm}$ and verified by densitometry of the 28S ribosomal RNA band separated on denaturing agarose gels (by Gel Doc 1000 Documentation System with Molecular Analyst/PC software; Bio-Rad, Hercules, CA, U.S.A.). Realtime PCR amplification $(39,40)$ was performed using rat IL-10, IL-12, IL-18, TNF- $\alpha$, IFN- $\gamma$, and TGF- $\beta$ PreDeveloped TaqMan Assay Reagents (Applied Biosystems, Foster City, CA, U.S.A.), as described in the manufacturer's protocol. Samples were subjected to 40 cycles of amplification at $95^{\circ}$ for $15 \mathrm{~s}$ followed by $1 \mathrm{~min}$ at $60^{\circ}$ using a GeneAmp 5700 Sequence Detection System (Applied Biosystems) according to the manufacturer's instructions. Water controls were included to ensure specificity. Relative quantification was used to determine the changes in steady-state mRNA levels between samples. Recently, Bustin (41) clearly showed significant limitations and inaccuracies in using housekeeping genes such as $\beta$-actin or GAPDH to normalize mRNA values. Therefore, we used relative quantification of steady-state mRNA levels between experimental groups, and all mRNA measurements were calculated on the basis of total RNA concentration (41). Separate standard curves for IL-10, IL-12, IL-18, TNF- $\alpha$, IFN- $\gamma$, and TGF- $\beta$ were generated from serial dilutions of nonexperimental intestinal cDNA. Real-time monitoring of fluorescent emission from cleavage of sequence-specific probes by the nuclease activity of Taq polymerase allowed definition of the threshold cycle during the exponential phase of amplification. Data were expressed as the fold induction of gene expression in RMS and RM groups compared with that in DF group.

Statistics. Statistical analyses between DF, RM, and RMS groups were performed by ANOVA followed by Fisher's PLSD, except for evaluating blood in stool and severity of NEC, which were analyzed using the Kruskal-Wallis Test followed by pair-wise comparison using the Mann-Whitney $U$ Test. All statistical analyses were performed using the statistical program Statview for Macintosh computers (Abacus Concepts Inc., Berkeley, CA, U.S.A.). $P<0.05$ was considered significant at the $95 \%$ confidence level. All expressed data are as the mean \pm SEM.

\section{RESULTS}

Effects of RM feeding on body weight gain. Body weights in the RMS group gradually decreased during the study period. In contrast, animals from the RM group maintained the same body weights in the initial half of the study, and then started gradually to gain in the second half of the experiment (Fig. 1). Differences in body weight between RMS and RM groups were statistically significant at $96 \mathrm{~h}(p<0.05)$. DF pups showed steady increases in body weight throughout the experiments. There were no differences in body weight gain of pups in the asphyxia/cold-stressed DF group compared with their nonstressed DF littermates (results not shown). These data indicate that artificial feeding of maternal milk is better tolerated and utilized than cow milk-based formula in developing neonatal rats but is still not as efficient as dam feeding.

Effects of RM on the severity and incidence of NEC. Blood in stool evaluations are routinely used in the diagnosis of human NEC; therefore, we applied this test in our experimental model. Because progression of intestinal damage typically 


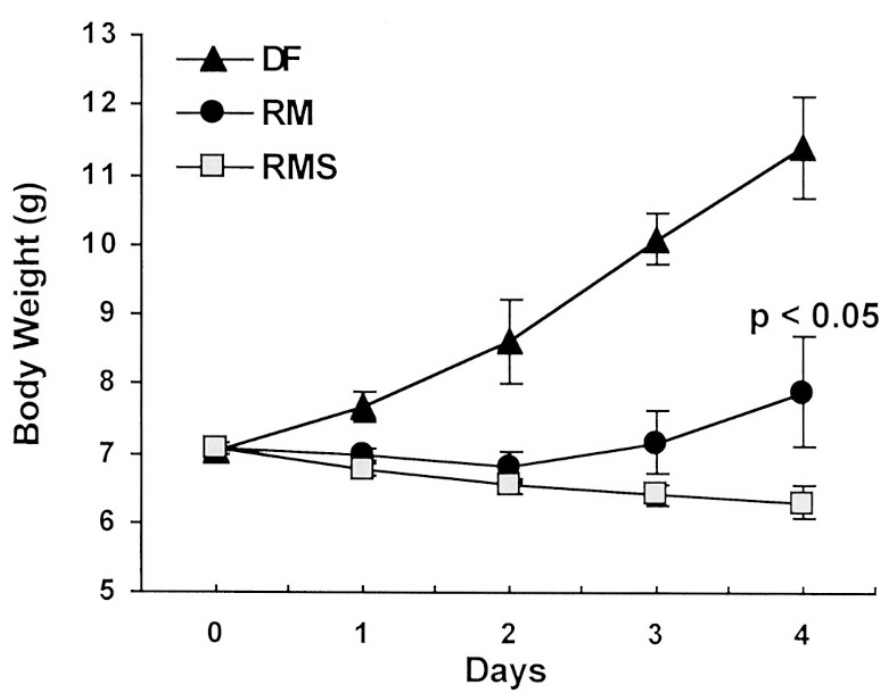

Figure 1. Body weight gain in neonatal DF rats $(n=10)$, artificially RM-fed rats $(n=13)$, and artificially RMS-fed rats $(n=15)$. Values are means \pm SEM; $p<0.05$ RMS $v s$ RM.

resulted in death, we performed guaiac measurements at $72 \mathrm{~h}$. The following scoring system was used: 0 , no blood in stools; 1, small traces of blood; 2 , moderate presence of blood; 3 , strong signal for the presence of blood; 4 , very strong signal for the presence of blood. The presence of blood in the stool was markedly higher in the RMS group $(p<0.01)$ compared with RM animals, with a median score of 3 and 1 , respectively. The median for blood in the stool values in DF group was 0 . Histologic analyses of ileal segments were performed using a scoring system from 0 to $4+$ to determine the severity of NEC as we have recently described (10). Results from these measurements are shown in Fig. 2A. In the RMS group, ileal architecture in most animals was significantly damaged (median NEC score $=2$ ) compared with the RM group (median NEC score $=1 ; p<0.01$ ). The median for histologic score of NEC in the DF group was 0.5 .

For determining the incidence of NEC, tissues with histologic scores $\geq 2+$ were designated NEC positive. Comparison of the overall incidence of NEC (Fig. $2 B$ ) revealed that $81 \%$ of RMS pups developed significant intestinal abnormalities described as moderate, severe, or full necrosis $(\geq 2+)$. In contrast, artificial feeding of RM significantly reduced the incidence of NEC to $26 \%$ (reduction by $55 \%$ compared with RMS littermates). None of the DF littermates showed histologic changes or abnormalities in ileal structure consistent with NEC. Results from histologic evaluations were confirmed by electron microscopy (EM). Scanning EM of the ileum from the DF group (Fig. $3 A$ ) exhibited smooth, well-preserved villi structure with Goblet cells scattered throughout the upper half of villi (Fig. 3D). In the RM group, the overall ileal structure looked similar to the DF littermates (Fig. 3B). Interestingly, higher magnification revealed mild disturbances in the villi brush border surface (Fig. 3E). In contrast, ileal sections from the RMS group confirmed pathologic changes and the damage of villi architecture (Fig. $3 C$ ) and the loss of epithelial integrity and enterocyte ruptures (Fig. $3 F$ ).
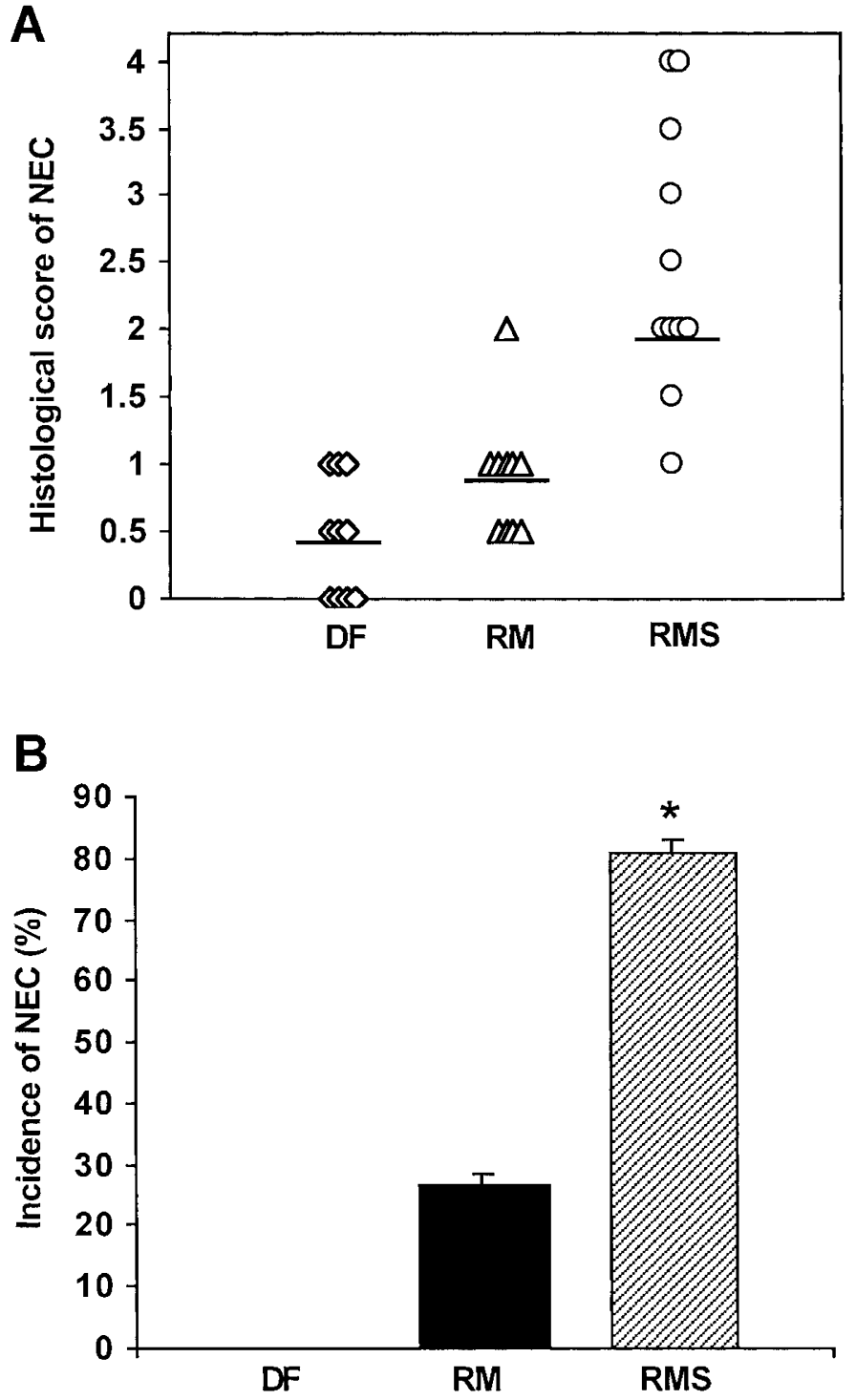

Figure 2. Histologic scores of NEC from ileal tissue $(A)$ and the incidence of NEC $(B)$ in animals from DF $(n=10)$, RM $(n=10)$, and RMS $(n=11)$ groups. For comparing the incidence of NEC from all studies, rats with ileal changes histologically scored $\geq 2+$ were considered NEC positive. The definition for each histologic grade was as follows: 0 , no damage; $1+$, slight submucosal and/or lamina propria separation; $2+$, moderate separation of submucosa and/or lamina propria, edema in submucosal and muscular layers; $3+$, severe separation of submucosa and/or lamina propria, severe edema in submucosal and muscular layers, regional villi sloughing; and $4+$, loss of villi and necrosis. In $B$, values are means \pm SEM; $* p<0.001$ RMS vs RM.

Effects of RM feeding on cytokine expression in ileum. We have previously reported increased production of proinflammatory cytokines IL-12 and IL-18 in ileal tissue of neonatal rats with NEC (34). For determining the mechanisms of the protective effect of maternal milk against NEC, a variety of pro-and anti-inflammatory cytokine mRNAs were measured in the ileum from DF, RM, and RMS groups, and results were compared with the severity of NEC injury. A quantitative real-time PCR technique was used to evaluate mRNA levels of IL-12, IL-18, TNF- $\alpha$, IFN- $\gamma$, IL-10, and TGF- $\beta$, and results are summarized in Table 1. Artificial feeding of both RMS or RM significantly elevated proinflammatory IL-12 and IL-18 



Figure 3. Scanning EM of ileum from DF ( $A$ and $D)$, RM ( $B$ and $E$ ), and RMS ( $C$ and $F$ ) groups. Ileal structure of rats from the DF group exhibited smooth, well-preserved villi structure without any obvious abnormalities $(A)$ with Goblet cells (arrow) scattered throughout the upper half of villi $(D)$. In the RM group, the overall ileal structure looked similar to the DF littermates $(B)$. However, higher magnification revealed mild disturbances in the villi brush border surface $(E)$. In contrast, the villi from the RMS group exhibited significant structural damage, such as short, swollen villi $(C)$, the loss of epithelial integrity on the villi surface, and enterocyte ruptures $(F)$.

Table 1. Pro- and anti-inflammatory cytokine $m R N A$ levels in ileum

\begin{tabular}{llll}
\multicolumn{4}{c}{ of neonatal rats } \\
\hline & $\begin{array}{c}\text { DF } \\
(n=10)\end{array}$ & $\begin{array}{c}\text { RM } \\
(n=11)\end{array}$ & $\begin{array}{c}\text { RMS } \\
(n=10)\end{array}$ \\
\hline IL-12 & $1.0 \pm 0.1$ & $2.2 \pm 0.4^{*}$ & $3.0 \pm 0.4^{*}$ \\
IL-18 & $1.0 \pm 0.1$ & $4.3 \pm 0.4^{*}$ & $3.4 \pm 0.4^{*}$ \\
TNF- $\alpha$ & $1.0 \pm 0.2$ & $0.9 \pm 0.3$ & $0.6 \pm 0.3$ \\
IFN- $\gamma$ & $1.0 \pm 0.2$ & $0.8 \pm 0.3$ & $1.4 \pm 0.3$ \\
IL-10 & $1.0 \pm 0.1$ & $8.2 \pm 2.3^{*}$ & $3.7 \pm 2.1 \#$ \\
TGF- $\beta$ & $1.0 \pm 0.1$ & $0.9 \pm 0.1$ & $1.0 \pm 0.1$ \\
\hline
\end{tabular}

All data are mean \pm SE.

$* P<0.01$ for DF rats $v s$ RM or RMS rats (ANOVA).

$\# P<0.05$ for RM rats $v s$ RMS rats.

mRNA levels compared with DF littermates but did not affect TNF- $\alpha$ and IFN- $\gamma$ gene expression. The elevation of IL- 12 and IL-18 in the RM group was unexpected, because the incidence and severity of NEC in this group were markedly reduced (by
55\%) compared with the RMS group. Therefore, gene expression of anti-inflammatory cytokines IL-10 and TGF- $\beta$ was evaluated (Table 1). IL-10 mRNA levels were increased $\sim 8$ fold $(p<0.01)$ in the RM group compared with DF littermates and $\sim 2$-fold $(\mathrm{p}<0.05)$ compared with RMS rats. There were no differences in TGF- $\beta$ mRNA levels.

Histologic localization of IL-10. Because cytokine mRNA measurements revealed significant up-regulation of IL-10 gene expression, IL-10 peptide production and histologic localization were performed using a confocal laser microscopy of the ileum (Fig. 4). Increased IL-10 was observed in the RM group (Fig. 4B) compared with both DF (Fig. 4A) and RMS (Fig. 4C) animals. In DF rats, mild to moderate IL-10 signal was detected in the cytoplasm of epithelial cells and occasionally in the lamina propria cells. In the RM group, strong IL-10 staining was localized predominantly in the cytoplasm of villus epithelial cells and in the crypt cells. Despite that ileal archi- 

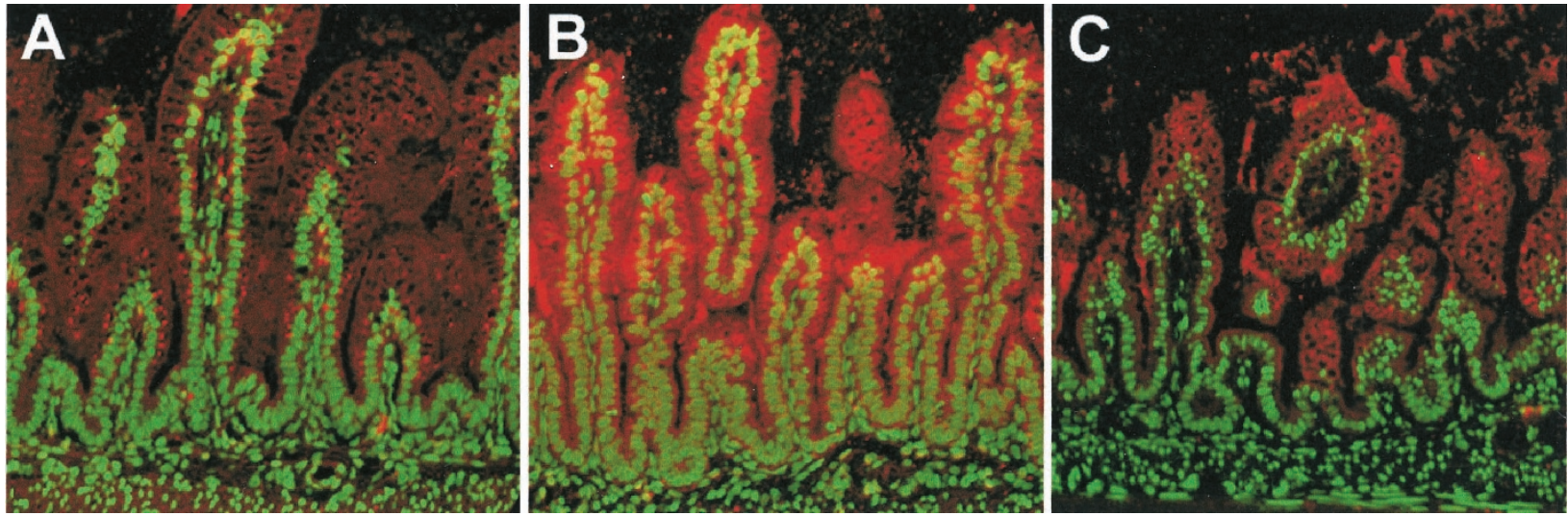

Figure 4. IL-10 localization in neonatal ileum. Representative sections from DF, RM, and RMS groups analyzed using confocal microscopy are shown. For this technique, nuclei are green and areas positive for IL-10 are red. (A) DF group, with moderate IL-10 signal localized predominantly in the cytoplasm of epithelial cells and occasionally in the lamina propria. $(B)$ RM group, with markedly increased expression in the cytoplasm of villus epithelial cells. $(C)$ RMS group, moderate to severe damage of villi architecture with IL-10 signal localized in epithelial cells of the upper half of villus. Magnification $\times 20$.

tecture from the majority of RMS rats exhibited moderate to severe damage, a significant number of IL-10 positive cells, localized mainly in the epithelium of the upper half of villi, was observed. Control serial section incubated without antiIL-10 antibody did not exhibit IL-10 signal (data not shown).

\section{DISCUSSION}

In the present study, we have shown that artificial feeding of RM collected during the early postnatal period significantly reduces the incidence and severity of NEC-like injury in the neonatal rat model. Similar to human NEC, enteral feeding of RM decreased but did not completely eliminate the development of disease. In addition, our results suggest that the mechanism by which this protection occurs is associated with increased endogenous production of anti-inflammatory IL-10 cytokine in the site of injury.

In $95 \%$ of cases, human NEC develops after the onset of enteral alimentation (42). Therefore, the composition and type of enteral diet plays a crucial role in the pathogenesis of neonatal NEC (6). A prospective multicenter study of 926 prematurely born infants demonstrated that NEC in formulafed infants was six to 10 times more frequent than in those fed with breast milk alone and three times more common than in those fed with infant formula plus breast milk (5). It is likely that biologically active molecules of maternal milk, such as hormones, cytokines, and growth factors, are the major factors in this protection against NEC (9). However, the individual components of milk and their mechanisms of protection against intestinal injury remain to be identified.

Despite the significant protective effect of maternal milk against NEC, even exclusive breast-feeding does not completely eradicate this disease. A study by Pitt et al. (19) using a rat NEC model suggested that freezing and thawing of collected RM completely eliminated its protective effect against NEC. However, the interpretation of results from this study is limited. First, all conclusions are based on the count of dead animals described as a NEC mortality, but there is no definition or characterization of NEC-like injury in this model. Our laboratory has many years of experience with artificial feeding of neonatal rats, and the mortality rate of the artificial rearing model may vary for many reasons other than intestinal injury $(35,43-45)$. Second, it is not clear at which stage of lactation RM was collected in that study. Dramatic changes in the composition of RM as lactation progresses are well documented (46). Results from the present study indicate that formula feeding is not wholly responsible for the development of disease. Although we did not detect NEC in DF neonatal rats, $\sim 26 \%$ of their littermates artificially fed with RM developed NEC-like injury. Possible explanations for this finding are that 1) the lack of maternal contact provides an additional stress factor that cannot be compensated for by RM alone, and/or 2) suckled pups receive maternal milk that matures in a time line compatible with their own growth and developmental needs. In addition, we speculate that the freeze-thawing process may partially destroy some components of maternal milk, resulting in reduction of but not complete amelioration of NEC.

Inflammatory mediators such as cytokines play an important role in many gastrointestinal diseases, including inflammatory bowel disease (IBD) (47). Evidence suggests that the risk factors for NEC induce an inflammatory cascade that results in the pathology associated with this disease (48), but cytokine profiles in NEC are poorly defined and often contradictory. In humans, TNF- $\alpha$ mRNA was increased in infants with severe NEC (29). However, plasma concentrations of TNF- $\alpha$ were similar regardless of disease severity (49). In a rat model, NEC-induced changes in TNF- $\alpha$ mRNA were not reported, but IFN- $\gamma$ mRNA showed a slight trend toward up-regulation and IL-12 mRNA was decreased in rats with severe $\operatorname{NEC}(31,50)$. We have previously reported increased IL-12 and IL-18 mRNA levels in rats with NEC and a correlation between increasing levels of these proinflammatory cytokines and tissue damage (34). We used real-time RT-PCR assay as opposed to the conventional RT-PCR method used by other laboratories $(31,50)$. This innovative method provides a more accurate and highly reproducible quantification of mRNA compared with conventional semiquantitative RT-PCR technique. In this study, artificial feeding of RM did not reduce elevated proin- 
flammatory IL-12 and IL-18 mRNA levels, even though there was a significant reduction in NEC development in this group. In addition, increased production of IL-18 peptide by ileal epithelial cells was observed in both RMS and RM groups (data not shown).

Recent reports indicate an important role of antiinflammatory cytokines such as IL-10 in NEC pathogenesis $(30,31)$. IL-10, which can be produced by monocytes, B-cells, Th-cells, and epithelial cells, has counterinflammatory properties such as suppression of synthesis of multiple proinflammatory cytokines and cell-mediated immunity $(30,51)$. In addition, IL-10 knockout mice spontaneously develop a chronic enterocolitis (52) and continuous administration of IL-10 prevents the development of IBD in the mouse experimental IBD model (53). Therefore, the alteration of endogenous production of IL-10 by intestinal epithelium in our rat experimental model of NEC probably has a critical role in NEC pathogenesis. We speculate that the differences in the incidence and severity of NEC between rats artificially fed RMS and RM relate to the inability of the RMS group to produce sufficient amounts of IL-10 to suppress overproduction of IL-12 and IL-18. The process of enteral feeding coupled with asphyxia/cold stress promotes increased production of IL-12 and IL-18 regardless of the composition of the diet. We speculate that animals enterally fed with RM are perhaps able to produce antiinflammatory IL-10 in quantities sufficient to counteract the affects of IL-12 and IL-18. In DF animals, we speculate that ileal IL-10 levels remain low because the low levels of proinflammatory IL-12 and IL-18, produced constitutively in normal intestine, are not damaging, and consequently, no additional IL-10 is required.

Bacterial colonization of premature intestine likely plays an important role in NEC pathogenesis $(54,55)$. Furthermore, administration of probiotics has been reported to decrease the incidence of NEC in both human (56) and animal studies (36). Although the molecular mechanisms underlying this beneficial effect is still not known, it has been shown that probiotic treatment induces endogenous production of IL-10 by intestinal mucosa (57). Although reduced incidence of NEC in neonatal rats fed with RM may be associated with changes in bacterial colonization of the developing intestine, further studies are needed to evaluate the association of bacterial colonization and cytokine production during NEC pathogenesis.

\section{CONCLUSION}

In conclusion, results from the present study clearly indicate that the neonatal rat model of NEC is a highly relevant and valuable model to study pathogenesis of human NEC. We have shown that the protective effects of maternal milk against NEC are associated with increased production of intestinal IL-10 in the neonatal rat model. Better understanding of the mechanisms underlying these protective effects will be beneficial either in the prevention of NEC or in the development of future therapeutic strategies to cure NEC.

\section{REFERENCES}

1. Caplan MS, Jilling T 2001 New concepts in necrotizing enterocolitis. Curr Opin Pediatr 13:111-115
2. Schanler RJ 2001 The use of human milk for premature infants. Pediatr Clin North Am 48:207-219

3. Lemons JA, Bauer CR, Oh W, Korones SB, Papile LA, Stoll BJ, Verter J, Temprosa M, Wright LL, Ehrenkranz RA, Fanaroff AA, Stark A, Carlo W, Tyson JE, Donovan EF, Shankaran S, Stevenson DK 2001 Very low birth weight outcomes of the National Institute of Child Health and Human Development Neonatal Research Network, January 1995 through December 1996. NICHD Neonatal Research Network. Pediatrics 107(1). Available at: www.pediatrics.org/cgi/content/full/107/1/e1

4. Kliegman RM 1999 Neonatal Necrotizing Enterocolitis. W.B. Saunders, Philadelphia, pp 445-465

5. Lucas A, Cole TJ 1990 Breast milk and neonatal necrotising enterocolitis. Lancet 336:1519-1523

6. Buescher ES 1994 Host defense mechanisms of human milk and their relations to enteric infections and necrotizing enterocolitis. Clin Perinatol 21:247-262

7. Hanson LA 1998 Breastfeeding provides passive and likely long-lasting active immunity. Ann Allergy Asthma Immunol 81:523-533

8. Walker WA 1997 Breast milk and the prevention of neonatal and preterm gastrointestinal disease states: a new perspective. Zhonghua Min Guo Xiao Er Ke Yi Xue Hui Za Zhi 38:321-331

9. Caplan MS, Amer M, Jilling T 2002 The role of human milk in necrotizing enterocolitis. Adv Exp Med Biol 503:83-90

10. Dvorak B, Halpern MD, Holubec H, Williams CS, McWilliam DL, Dominguez JA, Stepankova R, Payne CM, McCuskey RS 2002 Epidermal growth factor reduces the development of necrotizing enterocolitis in a neonatal rat model. Am J Physiol 282:G156-G164

11. Crissinger KD, Granger DN 1988 Characterization of intestinal collateral blood flow in the developing piglet. Pediatr Res 24:473-476

12. Di Lorenzo M, Bass J, Krantis A 1995 An intraluminal model of necrotizing enterocolitis in the developing neonatal piglet. J Pediatr Surg 30:1138-1142

13. Goldblum OM, Holzman IR, Fisher SE 1981 Intragastric feeding in the neonatal dog. Its effect on intestinal osmolality. Am J Dis Child 135:631-633

14. Garstin WI, Kenny BD, McAneaney D, Patterson CC, Boston VE 1987 The role of intraluminal tension and $\mathrm{pH}$ in the development of necrotizing enterocolitis: an animal model. J Pediatr Surg 22:205-207

15. Clark DA, Fornabaio DM, McNeill H, Mullane KM, Caravella SJ, Miller MJ 1988 Contribution of oxygen-derived free radicals to experimental necrotizing enterocolitis. Am J Pathol 130:537-542

16. Panigrahi P, Gupta S, Gewolb IH, Morris Jr JG 1994 Occurrence of necrotizing enterocolitis may be dependent on patterns of bacterial adherence and intestinal colonization: studies in Caco-2 tissue culture and weanling rabbit models. Pediatr Res 36:115-121

17. Krasna IH, Howell C, Vega A, Ziegler M, Koop CE 1986 A mouse model for the study of necrotizing enterocolitis. J Pediatr Surg 21:26-29

18. Barlow B, Santulli TV, Heird WC, Pitt J, Blanc WA, Schullinger JN 1974 An experimental study of acute neonatal enterocolitis - the importance of breast milk. J Pediatr Surg 9:587-595

19. Pitt J, Barlow B, Heird WC 1977 Protection against experimental necrotizing enterocolitis by maternal milk. I. Role of milk leukocytes. Pediatr Res 11:906-909

20. Caplan MS, Hedlund E, Adler L, Hsueh W 1994 Role of asphyxia and feeding in a neonatal rat model of necrotizing enterocolitis. Pediatr Pathol 14:1017-1028

21. Crissinger KD 1995 Animal models of necrotizing enterocolitis. J Pediatr Gastroenterol Nutr 20:17-22

22. Hsueh W, Caplan MS, Tan X, MacKendrick W, Gonzalez-Crussi F 1998 Necrotizing enterocolitis of the newborn: pathogenetic concepts in perspective. Pediatr Dev Pathol $1: 2-16$

23. Pacha J 2000 Development of intestinal transport function in mammals. Physiol Rev 80:1633-1667

24. Potoka DA, Nadler EP, Upperman JS, Ford HR 2002 Role of nitric oxide and peroxynitrite in gut barrier failure. World J Surg 26:7

25. Jung HC, Eckmann L, Yang SK, Panja A, Fierer J, Morzycka-Wroblewska E, Kagnoff MF 1995 A distinct array of proinflammatory cytokines is expressed in human colon epithelial cells in response to bacterial invasion. J Clin Invest 95:55-65

26. Insoft RM, Sanderson IR, Walker WA 1996 Development of immune function in the intestine and its role in neonatal diseases. Pediatr Clin North Am 43:551-571

27. Sanderson IR 1999 The physicochemical environment of the neonatal intestine. Am J Clin Nutr 69:1028S-1034S

28. Ford H, Watkins S, Reblock K, Rowe M 1997 The role of inflammatory cytokines and nitric oxide in the pathogenesis of necrotizing enterocolitis. J Pediatr Surg 32:275282

29. Viscardi RM, Lyon NH, Sun CC, Hebel JR, Hasday JD 1997 Inflammatory cytokine mRNAs in surgical specimens of necrotizing enterocolitis and normal newborn intestine. Pediatr Pathol Lab Med 17:547-559

30. Romagnoli C, Frezza S, Cingolani A, De Luca A, Puopolo M, De Carolis MP, Vento G, Antinori A, Tortorolo G 2001 Plasma levels of interleukin-6 and interleukin-10 in preterm neonates evaluated for sepsis. Eur J Pediatr 160:345-350

31. Edelson MB, Bagwell CE, Rozycki HJ 1999 Circulating pro- and counterinflammatory cytokine levels and severity in necrotizing enterocolitis. Pediatrics 103:766-771

32. Galliaerde V, Desvignes C, Peyron E, Kaiserlian D 1995 Oral tolerance to haptens: intestinal epithelial cells from 2,4-dinitrochlorobenzene-fed mice inhibit haptenspecific T cell activation in vitro. Eur J Immunol 25:1385-1390

33. Goldman AS 2000 Modulation of the gastrointestinal tract of infants by human milk Interfaces and interactions. An evolutionary perspective. J Nutr 130:426S-431S

34. Halpern MD, Holubec H, Dominguez JA, Williams CS, Meza YG, McWilliam DL, Payne CM, McCuskey RS, Besselsen DG, Dvorak B 2002 Upregulation of IL-18 and IL-12 in the ileum of neonatal rats with necrotizing enterocolitis. Pediatr Res 51:733-739 
35. Dvorak B, McWilliam DL, Williams CS, Dominguez JA, Machen NW, McCuskey RS, Philipps AF 2000 Artificial formula induces precocious maturation of the small intestine of artificially reared suckling rats. J Pediatr Gastroenterol Nutr 31:162-169

36. Caplan MS, Miller-Catchpole R, Kaup S, Russell T, Lickerman M, Amer M, Xiao Y, Thomson Jr R 1999 Bifidobacterial supplementation reduces the incidence of necrotizing enterocolitis in a neonatal rat model. Gastroenterology 117:577-583

37. Crowley CL, Payne CM, Bernstein H, Bernstein C, Roe D 2000 The NAD+ precursors, nicotinic acid and nicotinamide protect cells against apoptosis induced by a multiple stress inducer, deoxycholate. Cell Death Differ 7:314-326

38. Dvorak B, Kolinska J, McWilliam DL, Williams CS, Higdon T, Zakostelecka M, Koldovsky O 1998 The expression of epidermal growth factor and transforming growth factor-alpha mRNA in the small intestine of suckling rats: organ culture study. FEBS Lett 435:119-124

39. Brieland JK, Jackson C, Menzel F, Loebenberg D, Cacciapuoti A, Halpern J, Hurst S, Muchamuel T, Debets R, Kastelein R, Churakova T, Abrams J, Hare R, O'Garr A 2001 Cytokine networking in lungs of immunocompetent mice in response to inhaled Aspergillus fumigatus. Infect Immun 69:1554-1560

40. Gibson UE, Heid CA, Williams PM 1996 A novel method for real time quantitative RT-PCR. Genome Res 6:995-1001

41. Bustin SA 2000 Absolute quantification of mRNA using real-time reverse transcription polymerase chain reaction assays. J Mol Endocrinol 25:169-193

42. Anderson DM, Kliegman RM 1991 The relationship of neonatal alimentation practices to the occurrence of endemic necrotizing enterocolitis. Am J Perinatol 8:62-67

43. Stepankova R, Dvorak B, Sterzl J, Trebichavsky I 1990 Effects of essential fatty acids deficiency in milk diets on the development of germ-free and conventional rats. Physiol Bohemoslov 39:135-146

44. Dvorak B, Stepankova R 1992 Effects of dietary essential fatty acid deficiency on the development of the rat thymus and immune system. Prostaglandins Leukot Essent Fatty Acids 46:183-190

45. Philipps AF, Anderson GG, Dvorak B, Williams CS, Lake M, Lebouton AV, Koldovsky O 1997 Growth of artificially fed infant rats: effect of supplementation with insulin-like growth factor I. Am J Physiol 272:R1532-R1539
46. Keen CL, Lonnerdal B, Clegg M, Hurley LS 1981 Developmental changes in composition of rat milk: trace elements, minerals, protein, carbohydrate and fat. J Nutr 111:226-236

47. Mahida YR 2000 The key role of macrophages in the immunopathogenesis of inflammatory bowel disease. Inflamm Bowel Dis 6:21-33

48. Caplan MS, MacKendrick W 1994 Inflammatory mediators and intestinal injury. Clin Perinatol 21:235-246

49. Morecroft JA, Spitz L, Hamilton PA, Holmes SJ 1994 Plasma cytokine levels in necrotizing enterocolitis. Acta Paediatr Suppl 396:18-20

50. Nadler EP, Dickinson E, Knisely A, Zhang XR, Boyle P, Beer-Stolz D, Watkins SC, Ford HR 2000 Expression of inducible nitric oxide synthase and interleukin-12 in experimental necrotizing enterocolitis. J Surg Res 92:71-77

51. Chheda S, Palkowetz KH, Garofalo R, Rassin DK, Goldman AS 1996 Decreased interleukin-10 production by neonatal monocytes and $\mathrm{T}$ cells: relationship to decreased production and expression of tumor necrosis factor-alpha and its receptors. Pediatr Res 40:475-483

52. Kuhn R, Lohler J, Rennick D, Rajewsky K, Muller W 1993 Interleukin-10-deficient mice develop chronic enterocolitis. Cell 75:263-274

53. Rennick DM, Fort MM 2000 Lessons from genetically engineered animal models. XII. IL-10-deficient (IL-10(-/-)) mice and intestinal inflammation. Am J Physiol 278:G829-G833

54. Claud EC, Walker WA 2001 Hypothesis: inappropriate colonization of the premature intestine can cause neonatal necrotizing enterocolitis FASEB J 15:1398-1403

55. Marteau PR 2002 Probiotics in clinical conditions. Clin Rev Allergy Immunol 22:255-273

56. Hoyos AB 1999 Reduced incidence of necrotizing enterocolitis associated with enteral administration of Lactobacillus acidophilus and Bifidobacterium infantis to neonates in an intensive care unit. Int J Infect Dis 3:197-202

57. Ulisse S, Gionchetti P, D’Alo S, Russo FP, Pesce I, Ricci G, Rizzello F, Helwig U, Cifone MG, Campieri M, De Simone C 2001 Expression of cytokines, inducible nitric oxide synthase, and matrix metalloproteinases in pouchitis: effects of probiotic treatment. Am J Gastroenterol 96:2691-2699 